\title{
LA DEMOCRACIA CONTEMPORÁNEA Y SUS FUNDAMENTOS medievales. Marsilio de Padua y la Justificación RACIONAL DE LOS PRINCIPIOS NORMATIVOS DEL ESTADO
}

\author{
Mauricio Chapsal Escudero ${ }^{1}$ \\ Roberto Castillo Vallejos ${ }^{2}$
}

RESUmen: En el presente artículo se pretende, junto con ampliar las referencias de interpretación y caracterización del pensamiento social y político de la Edad Media, rastrear, por medio de los aportes de Marsilio de Padua, las posibles fuentes o referencias que, en el contexto de las discusiones de los siglos XIII-XIV, pueden verse contenidas en los márgenes de las fundamentaciones de las democracias contemporáneas, incluyendo, para el caso, las discusiones en torno al liberalismo político (Habermas) y el imperativo del pluralismo (Rorty).

Palabras Claves: Pensamiento político medieval. Democracia contemporánea. Liberalismo político. Pluralismo.

\section{INTRODUCCION}

Las democracias contemporáneas occidentales, contenidas en lo que conocemos como "liberalismo político", se entienden "como una justificación no religiosa y postmetafísica de los principios normativos del Estado constitucional democrático." (HABERMAS; RATZINGER, 2008, p. 11). El problema teórico-político fundamental contenido en esta definición, en especial cuando se siguen los pasos de Kant, tal cual es el caso de Habermas, por ejemplo, dice relación con la posibilidad efectiva de que este Estado liberal y secularizado pueda lograr sustentarse en presupuestos normativos que, a fin de cuentas, él mismo no puede ya garantizar, en oposición, claro está, a las garantías supuestas en los presupuestos metafísicos o religiosos.

\footnotetext{
${ }^{1}$ Profesor Asociado del Departamento de Filosofía de la Universidad de Santiago de Chile, Santiago - Chile. E-mail: mauricio.chapsal@usach.cl

2 Profesor del Programa de Bachillerato de la Universidad de Santiago de Chile, Santiago - Chile. E-mail: rubespino@gmail.com
} 
Pero no es éste el único problema al que se enfrenta una discusión en torno a las democracias contemporáneas. Tras dicho modelo se esconde, además, una larga discusión filosófica e histórica que, lamentablemente, pocas veces se especifica y que, en otros no pocos casos, induce a errores fundamentales respecto a las referencias críticas a las que se orientan las democracias modernas, o el liberalismo político, para ser más precisos. A este respecto, un par de observaciones.

La primera observación, dice relación con el problema de reconocer el verdadero contexto histórico-político contra el cual se enfrentan las democracias contemporáneas. De más está decir que se ha vuelto un lugar común considerar a la Edad Media como un todo según la caricatura de "tiempos de monjes", esto es, como un tiempo gobernado por los influjos intelectuales y religiosos monásticos, que, a decir en justeza, sólo se condensa entre los siglos X y parte del siglo XI. Es decir, y ante el monopolio religioso y metafísico del clero en dicho espacio de tiempo, la modernidad, y en especial su modelación política, aparece como una ruptura, como un "tiempo nuevo", donde lo fundamental radica en criterios como los de un origen racional del Estado, la idea de soberanía del pueblo, o bien el consenso como un criterio fundamental para la legitimidad del poder en todas sus dimensiones.

La segunda observación, que se desprende de la antes expuesta, resulta algo más crítica. Dice relación con la también difundida idea de que la modernidad, en especial su modelación política, y si bien reconocida en sus fuentes con aportaciones fundamentales de la Grecia clásica, se alza como una particularidad histórico-cultural autónoma, del todo independiente, por sus radicales diferencias, respecto de tiempos pretéritos, en especial el medioevo. Tan "oscura” resulta la Edad Media, que ningún destello de luz pudo penetrar, desde ella, en lo que conocemos como modernidad.

De estas dos observaciones se desprenden dos interrogantes; a saber: 1) ¿resulta correcto reducir al medioevo al "tiempo de monjes", o podemos reconocer diferencias al interior de dicho periodo que nos permitan establecer precisiones más ajustadas con la verdadera naturaleza del pensamiento medieval en su totalidad? 2) si dicha diferenciación es posible, ¿no podría con ella cambiar nuestras nociones reduccionistas respecto al medioevo, y como consecuencia de ello, mejorar nuestras precisiones entorno a los fundamentos de nuestras democracias contemporáneas? 
En este artículo pretendemos dar respuesta a estas dos interrogantes, es decir, precisar y poder, desde ahí, reconocer diferencias en el contexto del pensamiento medieval de forma tal de salir de su reduccionismo en la figura "tiempo de monjes"; alcanzado esto, ver si podemos reconocer en el propio medioevo criterios fundamentales contenidos en nuestras democracias contemporáneas.

A modo de tesis, sostendremos lo siguiente: que Marsilio de Padua (1275/80 - 1343) condensa una diferencia fundamental en el contexto del pensamiento medieval, y que, en cuanto tal, bien podemos reconocer en él, en su pensamiento, algunos de los criterios fundamentales contenidos en nuestras democracias contemporáneas y su particular pretensión de justificación no religiosa y postmetafísica ${ }^{3}$.

Para tales efectos, hemos organizado nuestra exposición de la siguiente manera: primero (II), estableceremos una diferenciación en el pensamiento filosófico y político de la Edad Media con el propósito de, así como demostrar el reducido foco de atención crítica que tiene y ha tenido la modernidad respecto a dicho periodo (tiempos de monjes), poder marcar la especificidad del pensamiento del Paduano, que, aun cuando rupturista respecto de muchos y muy fundamentales criterios y fundamentos medievales, sigue siendo un pensador de su tiempo. Luego de esto (III), tomaremos algunos criterios esenciales de su pensamiento con el fin de reconocer en ellos no pocos fundamentos, aún vigentes, de nuestras democracias contemporáneas, de nuestro liberalismo político, en especial el imperativo del pluralismo, cuyas raíces podemos, precisamente, reconocer en el paduano.

\section{Sociedades y Políticas en el Pensamiento medieval}

Tal cual hemos dicho, se suele encerrar en un todo el pensamiento del medioevo, sea político como filosófico. Las imágenes comunes, a este respecto, se suelen imponer, no pocas veces, a las aportaciones que han hecho tanto la historia como la propia filosofía. Salir de este reduccionismo sin duda aporta a una discusión más rica y provechosa en los contextos políticos y sociales modernos, en especial en lo que dice relación con las democracias contemporáneas y su liberalismo político. He aquí el sentido de una precisión como la que buscamos exponer.

${ }^{3}$ La fuente principal de nuestro estudio es la obra de Marsilio Sobre el poder del imperio y del papa. El defensor menor. La transferencia del imperio. Madrid: Biblioteca Nueva, 2005. 
Bien es sabida la pretensión que subyace en San Agustín y su obra $L a$ ciudad de Dios; a saber: bajo la distinción entre Estado e Iglesia, proponer una purificación y transformación de los valores de la acción política por medio de la fe cristiana. Esta distinción entre la auctoritas del sacerdote -en cuestiones de religión y moral- y la potestas política del gobernante se rastrea hasta las cartas del Papa Gelasio I y el emperador Anastasio (JUAN DE SALISBURY, 1984, p. 53). Si bien se advierte un criterio de orientación de la auctoritas respecto a la potestas, tal cual en San Agustín, lo que se impone es una diferenciación entre uno y otro espacio social, en el entendido -retomado más tarde- de que para unos y otros, para sacerdotes y gobernantes, los alcances de su quehacer difieren en su naturaleza fundamental: material y finita para unos (gobernantes), espiritual e infinita para los otros (sacerdotes).

Dos siglos más tarde, en occidente, dicha diferenciación se rompe, o bien se impone en su lugar un criterio de jerarquización en extremo relevante. La caída del Imperio Romano aparece como una de las causas fundamentales de este giro, y esto por la siguiente razón: la caída del imperio deja como guía o fuente de definiciones doctrinales a la Iglesia, con lo cual el pensamiento político se ve absorbido por distinciones de orden religioso. Como un ejemplo, se citan los textos del Papa Gregorio Magno (590 - 604): Regula pastoralis y su Moralia in Job. En estos, se deja establecido, entre otros, el siguiente criterio: el gobierno es un orden impuesto por Dios para combatir las inclinaciones viciosas de los hombres, tocados por el mal (JUAN DE SALISBURY, 1984, p. 53). De una idea semejante se desprenden dos conclusiones gravitantes para los siglos venideros: el gobierno, las funciones administrativas del gobernantes, se conciben como queridas por Dios; y por dicha razón, el gobernante debe ser instruido moralmente para que su acción se ajuste a los imperativos dictados por Dios. Dicho de otro modo: un rey, un gobernante que no se ajuste a dichos imperativos, o cae en tiranía, o bien pierde su condición de tal por el pecado, criterio que se consolida en el Concilio de Toledo (año 633) atribuyendo al clero la función central de instrucción teórica de los príncipes en lo concerniente a las esferas ético-religiosas, postergando las de orden políticas y administrativas (JUAN DE SALISBURY, 1984, p. 53).

Establecida la jerarquización entre auctoritas y potestas, se da paso a la proyección de dicho criterio para el orden general de la sociedad, lo que en lenguaje moderno se conoce como diferenciación funcional (RODRIGUEZTORRES, 2008, p. 427). Así, y en primer lugar, tenemos una jerarquización al interior de la propia Iglesia: órdenes de vírgenes o monjes, continentes 
o sacerdotes, casados o seglares, lo que ya incuba uno de los aportes más significativos en el pensamiento de los autores de la renovación literaria carolingia de los siglos VIII y IX: el que el reparto del poder es desigual, y que dicha desigualdad es querida por la Providencia como forma para combatir el mal. En autores como San Bonifacio, y más tarde Agobardo de Lyon (833), se impone esta idea de jerarquización funcionalista de la sociedad, con un criterio central de orden orgánico, lo cual se traduce en las distinciones clero-pueblo, poderosos-débiles, libres-siervos y en la función del rey como el coordinador de dichas diferencias (JUAN DE SALISBURY, 1984, p. 54). A este funcionalismo orgánico, los autores del tiempo carolingio agregarán un criterio que se podrá rastrear hasta mediados del siglo XI; a saber: la divinización de los principios de autoridad y desigualdad, así como las diferencias funcionales y el orden social producto de la misma.

Por la influencia política y social que adquiere el clero, y en especial los monasterios, por concentrar gran parte de la actividad filosófica y espiritual, durante este periodo de tiempo, es que a los siglos X y XI, sobre todo, se le conoce como "tiempo de monjes". Tiempo, éste, empero, que decae a mediados del siglo XI, y que se pierde definitivamente en los siglos XII y XIII, por causas bien precisas: auge de la comunidad política, incremento de las universidades y su presencia o influencia en cortes y parlamentos (JUAN DE SALISBURY, 1984, p. 56). Causas de este tipo llevan a lo que se considera una de las particularidades propias de los siglos XI al XII: junto con la expansión de los regímenes feudo-vasalláticos, la reforma eclesiástica. En el contexto de esta reforma, encontramos las disputas en torno a la forma en que deben encausarse las aportaciones, o la función de la Iglesia, en vistas a conseguir el orden, es decir, el fin superior establecido ya por Dios en las Escrituras. Pero es una discusión que, si bien sus orígenes ya hemos rastreado, se da en el contexto de cambios culturales y sociales bastante decidores: los monjes, el monasterio, por ejemplo, dejan de detentar el poder de las influencias rectoras en la formación de los príncipes, dando paso al clérigo secular, como lo es el propio Juan de Salisbury. Este cambio supone, entre otras cosas, una redefinición de los espacios de influencia.

Una pregunta adquiere aquí un profundo sentido: ¿de quién depende, de quién se obtiene, la libertad eclesiástica, la que se sigue considerando fundamental para el correcto funcionamiento de la sociedad? La respuesta a esta pregunta dará las formas de lo que conoceremos como "vida apostólica", a saber: dicha libertad se obtiene a través de la autoridad del rey, y no contra 
ella, que será, entre otras, la posición de Juan de Salisbury como base para su Policraticus. Y más aún: el servicio a la monarquía y el servicio a la Iglesia serán considerados como dos frentes de una misma actividad, actividad que no es otra que conducir a la sociedad hacia el bien, mas no desde fuera, como era el caso del monje, del monasterio, sino desde dentro, actuando en su interior, tal cual lo dictan los ideales de la vida apostólica que se desarrollará a partir de finales del siglo XI (JUAN DE SALISBURY, 1984, p. 59).

Este actuar dentro de resultará gravitante en las discusiones filosóficas, teológicas y políticas a contar de fines del siglo XIII y mediados del XIV, tiempo en el que ubicamos a Marsilio de Padua. Entre otras cosas, volverá evidente la tensión entre lo que podríamos denominar órbitas de poder, esto es, entre los problemas de éste mundo -que remiten al ahora-y los del otro-que remiten a la incondicionalidad de la vida después de la muerte. Pero junto con esto, la participación del clérigo secular dentro de la sociedad volverá evidente también las disputas políticas tanto del gobernante, el rey, como de la Iglesia, centrada muy fuertemente ya en la figura del Papa. Dos caras, como se puede advertir, de la misma moneda.

A partir de estas tensiones, se vuelve manifiesto, ya no el primado de un poder sobre otro, a la manera de orientación fundamental de la Iglesia respecto del gobernante, tal cual vimos no hace mucho, sino la pugna entre estos dos poderes. ¿Pero se puede hablar efectivamente, y en justeza, de “dos” poderes? ¿Qué es el poder, cuál su naturaleza y alcances? ¿En qué se fundamenta el poder de la Iglesia, del Papa, y en qué lo hace el poder del gobernante, del rey? ¿Pueden ambos conjugarse, coordinarse, tal cual se sostenía en los siglos VIII y IX, o resultan contradictorios uno respecto del otro cuando se trata del orden social?

Son preguntas de éste tipo las que afloran cuando del convento se pasa a la participación directa del clérigo en los asuntos humanos y sociales, porque estar dentro de ya no sólo posibilita la instrucción moral y religiosa de los príncipes, o la orientación general por vía del gobernante, tal cual lo seguirá pretendiendo Juan de Salisbury (1115/20-1180), sino que expone, críticamente, además, competencias de naturaleza distinta que, tal cual lo veremos, socavan, o ponen en entredicho, los criterios y fundamentos de la legitimidad del poder, así como los propios alcances del poder Papal.

En tal contexto, muy lejos ya del "tiempo de monjes", nos encontramos con un tipo de razonamiento y fundamentación crítica, que, 
aún en los límites del medioevo, resaltan por su proximidad con los que hoy nos son tan familiares, y malamente concebidos como propios de un contexto social distante y ajeno al medieval. Por ejemplo, en Marsilio de Padua encontramos tópicos como los siguientes, resaltados, a juicio de Bernardo Bayona y Pedro Roche (MARSILIO DE PADUA, 2005, p. 13) por Otto Von Gierke en su obra Teorías politicas de la Edad Media (2010, p. 166 y sgtes.): a) el origen racional del Estado; b) la soberanía del pueblo; c) el carácter representativo de la ley; d) el consenso como criterio de legitimidad; e) y la importancia de la elección del gobernante. $\mathrm{O}$ bien podemos tomar como ejemplo la tesis de Marsilio en su obra El defensor de la paz, en el contexto de pugna entre el Papa Juan XXII y el Emperador Luis IV; a saber: cuando el Papa asienta la discordia, el Emperador, como defensor de la paz, tiene la autoridad y el deber de convocar el Concilio General (MARSILIO DE PADUA, 2009, p 369).

En efecto, es en el medioevo donde, con Marsilio, la posibilidad de la paz, del orden social, se concibe como resultante de las competencias del poder secular, del gobernante, y ya no del clero, o el Papa; es más, y tal cual será el objetivo del texto El defensor menor, que luego revisaremos con algo más de detención, destruir los fundamentos de la doctrina pontificia de la plenitud de poder resulta, para nuestro autor, fundamental para la consecución de la paz; o en otras palabras: la paz depende de la destrucción de una ilegítima ambición papal, tal cual es el fundamento de la plenitud de poderes (MARSILIO DE PADUA, 2005, p. 43-44).

Pero no confundir: Marsilio sigue siendo un pensador del medioevo. A diferencia del pensamiento del renacimiento, o bien de la propia Ilustración, nuestro autor no niega ni desconoce los órdenes referenciales sacrotrascendentales, ni pone en entredicho los fundamentos de orden metafísico que rastrea tanto en aportes griegos, como Aristóteles (MARSILIO DE PADUA, 2005, p. 136), como a nivel de las Escrituras. Son todas estas fuentes válidas para, aunque en apariencia contradictorio, fundamentar, críticamente, los límites de la jurisdicción eclesiástica (tal cual ocurre en su obra Defensor minor, aparecida entre fines del año 1341 y comienzos del año 1342), o bien para justificar la transferencia del imperio en razones y hechos políticos, y rechazar así las justificaciones de orden teológicas tradicionales vigentes entonces (como en su obra De translatione imperii, redactada entre los años 1324 y 1326). 


\section{MARSILIO DE PADUA Y LOS FUNDAMENTOS DE LAS DEMOCRACIAS CONTEMPORÁNEAS}

Para adentrarnos en la obra del filósofo medieval, en el contexto de discusión que hemos venido exponiendo, tomaremos, como fuente de análisis, su libro Defensor minor, cuya tesis central puede quedar expuesta de la siguiente manera: la unidad del poder secular y la exclusión completa de cualquier jurisdicción sacerdotal (MARSILIO DE PADUA, 2005, p. 27). Nuestro propósito aquí es el siguiente: reconocer en estos aportes no pocos fundamentos, aún vigentes, de nuestras democracias, de nuestro liberalismo político, en especial el imperativo del pluralismo, cuyas raíces podemos, precisamente, reconocer en el paduano.

Pero sería una franca alteración de los límites y pertinencias de la obra de Marsilio tomarlo como base o como fuente directa del pensamiento moderno propiamente tal, o no ver en los fundamentos políticos modernos más que una simple copia, un plagio, de los aportes de nuestro autor. Ni lo uno, ni lo otro. Vale, entonces, precisar lo siguiente: en nuestro objetivo se desprende la intención, general por cierto, de ampliar los horizontes con los cuales se ha entendido o interpretado al medioevo, así como reconocer en los postulados del paduano criterios fundamentales, muchos de ellos aún vigentes, del pensamiento político moderno, sino contemporáneo.

Para el logro del objetivo propuesto, seguiremos dos líneas de discusión. Primero (II-A), tomaremos un par de criterios problemáticos que, a juicio de Habermas, resultan fundamentales en los contextos de las democracias contemporáneas, para ver hasta dónde, o en qué medida, ya éstos se encuentran presentes en la obra del autor medieval. Segundo (II-B), y para ver hasta dónde podemos rastrear en él las raíces del pluralismo en el que se asientan las democracias contemporáneas, tomaremos una de las tesis centrales de R. Rorty respecto a la distinción sacro-secular como superación fundamental para la consecución de un tipo de sociedad asentada efectivamente en un orden noautoritario, esto es, pluralista, tesis que encontramos claramente expuesta en su obra El pluralismo, una versión. Antiautoritarismo en epistemología y ética (RORTY, 2000). Veamos.

II-A. Para Habermas, quien para esto sigue los pasos de Kant, algunos de los problemas fundamentales contenidos en las democracias modernas, esto es, en los órdenes políticos postmetafísicos, y cuyos fundamentos ya no descansan en criterios de orden religioso -y cuya configuración se inicia con el contractualismo-, son los siguientes: a) saber si se puede alcanzar un poder 
político de justificación secularizada, es decir, no religiosa o postmetafísica; b) un ordenamiento liberal necesitaría siempre de la solidaridad de sus ciudadanos como fuente, pero esta fuente podría desaparecer a causa de una secularización "descarrilada"; c) cuáles son las actitudes cognitivas y cuáles las expectativas normativas que el Estado liberal tendría que exigir a ciudadanos creyentes y no creyentes en su relación mutua (HABERMAS; RATZINGER, 2008, p. 10-11).

Si bien en Marsilio no encontramos una formulación similar de problemas, sí podemos sostener que en el pensamiento del paduano se alzan criterios semejantes y respuestas muy particulares al respecto. En estas se sigue un razonamiento que arranca de una definición de poder para luego diferenciar dos órdenes, a su juicio completamente distintos, de influencia o ejercicio: el temporal y el espiritual. Este razonamiento sostiene lo siguiente, en base al poder de los sacerdotes de atar y desatar ${ }^{4}$ :

Si este poder se denomina jurisdicción, y jurisdicción consiste en la dictio iuris, es decir, pronunciar el derecho, (dicere ius), y derecho es lo mismo que ley, entonces podemos reconocer dos tipos de ley: la ley divina y la ley humana [...]. La ley divina debe entenderse como un precepto inmediato de Dios, sin deliberación humana, para saber qué hacer en esta vida con el sólo fin de alcanzar lo mejor en la otra vida [...]. La ley humana, por su parte, debe entenderse como un precepto coactivo del conjunto de los ciudadanos, o de su parte prevalente, para deliberar sobre los actos humanos voluntarios en esta vida, para alcanzar el mejor estado en esta vida. (MARSILIO DE PADUA, 2009, p. 87-89).

Hecha estas precisiones, nuestro autor se centra en cuatro significados de "decir la ley"; a saber: a) el de descubrir la norma o razón de los actos civiles, y que la dicen los hombres que las descubren; b) decirla o exponerla a otro, tal cual lo hacen los doctores en ley; c) promulgarla en forma de precepto coactivo, con carácter general para todos los que deban someterse a ella o aplicarla, tal cual lo hace el legislador; d) se entiende bajo la forma de un precepto coactivo dirigido en particular a cada uno de sus transgresores, tal cual lo hace, también, el legislador.

Tomadas las precisiones iniciales sobre los dos tipos de ley, y dados los significados del "decir la ley", Marsilio de Padua (2005, p.90-91) afirmará lo siguiente:

\footnotetext{
${ }^{4}$ Que Marsilio aclara haber discutido en su obra El defensor de la Paz.
} 
Primero: que ningún hombre ha podido dictar la ley divina en el sentido a, c y d; de esto se deduce, que ningún hombre tiene poder o autoridad para dispensar, cambiar, añadir o suprimir nada de los preceptos de la ley divina.

Segundo: que dictar la ley humana conforme a los significados c y d no corresponde de por sí a ningún Obispo, Sacerdote o Diácono; se infiere de esto que ni el Obispo de Roma, ni ninguno de los ministros de la Iglesia, tiene ni ha tenido nunca jurisdicción coactiva en este mundo sobre clérigo o laico alguno, salvo que tal jurisdicción le hubiera sido concedida por el legislador humano, en cuyo caso bien le podría ser revocada.

Como referencia fundamental para este razonamiento, nuestro autor recurre a la II Epístola a Timoteo: "Ningún soldado de Dios se implica en negocios humanos." (MARSILIO DE PADUA, 2005, p. 93).

En el pensamiento del Paduano, y como se puede advertir, lo fundamental, que supone, además, una variante respecto a Aristóteles, y por esta vía, con Santo Tomás de Aquino 5 (MARSILIO DE PADUA, 2005, p. 41 42), es la dimensión coactiva que supone el poder terrenal, el del gobernante, y que no se encuentra presente en el espiritual, o sacerdotal. "Las armas de nuestra milicia no son carnales", apunta la II Carta a Corintios, y que Marsilio rescata como fundamento para su tesis. Es cierto, Cristo confirió poderes a sus apóstoles, como los de bautizar, celebrar la eucaristía, o convertir el pan en su cuerpo, incluso el de atar y desatar los pecados a los hombres en esta vida para alcanzar la felicidad en la otra vida, mas ninguno de estos poderes contiene o supone la posibilidad de coacción física o material (MARSILIO DE PADUA, 2005, p. 98). De aquí que para el Paduano lo más cercano a los sacerdotes, en relación a sus poderes, sea el del médico, quien puede dar una opinión al hombre sano o enfermo.

En términos de Marsilio, los problemas a y b que expone Habermas, exigen de una distinción fundamental: la que se da entre el poder espiritual y el poder coactivo de la jurisdicción. Si bien la primera es una prerrogativa del clero, o del Obispo de Roma, la segunda lo es en exclusividad del gobernante, del rey, o, lo que resulta muy decidor, de la parte prevalente de la sociedad o comunidad en cuestión. Es decir: la jurisdicción, tomada en su sentido más estricto, exige de una condición de sujeción material, terrenal, a mérito de

${ }^{5}$ Esto, porque el carácter coactivo, más que derivarse de la esencial justicia de la ley (Aristóteles), se convierte en condición de la existencia de la ley y, por ende, en precondición de la justicia (Marsilio de Padua). 
que sus objetivos y alcances sólo remiten a esta vida, y no interfieren o no condicionan a la otra vida. El gobernante, que detenta este poder coactivo, no logra sus objetivos respecto al orden social sólo enseńando, exhortando o argumentando, tal cual sí lo pueden hacer los sacerdotes; el orden social terrenal es una responsabilidad del poder en la medida de que, así como las acciones, sus consecuencias intervienen en los márgenes materiales del quehacer social.

Otro criterio decidor, a este respecto, y que compromete el tercer problema de Habermas, dice relación con el sentido general de autoridad, o de supremacía, sea entre el gobernante y el Papa, bien lo sea del Papa respecto a la totalidad de los estamentos sociales, incluido el propio clero. El razonamiento que sigue aquí nuestro autor medieval es el siguiente:

Ningún apóstol, ni hombre, ha sucedido ni puede suceder a Cristo en cuanto Dios ni en cuanto Dios y hombre juntos; por consiguiente, esta plenitud de poder no pudo corresponder a ningún apóstol sucesor, puesto que ninguno de ellos tuvo ni tiene ambas naturalezas, humana y divina, en una sola personal. (MARSILIO DE PADUA, 2005, p. 128).

Pero el razonamiento no queda aquí; va y compromete la naturaleza misma de lo que llamamos fe ajustada a lo revelado. Así, Marsilio de Padua (2005, p. 130) dirá:

No recuerdo haber leído en la Escritura, ni en nada que derivara por necesidad de la Escritura, que dicho primado (el del Papa) haya sido concedido a San Pedro o a la Iglesia Romana directamente por Dios o Cristo. Luego, creerlo no es cuestión de necesidad para la salvación eterna.

¿Quién, o quienes, tienen entonces la primacía, la autoridad? En el capítulo XII de la obra en comento encontramos la siguiente respuesta; a saber:

El supremo legislador humano fue, es y debe ser el conjunto de los hombres que deben someterse a los preceptos coactivos de la ley, o su parte prevalente en cada región o provincia [...] esta potestad debe durar $\mathrm{y}$ es probable que dure mientras no le sea retirado al pueblo romano por el conjunto de las provincias o por el pueblo romano a su príncipe. (MARSILIO DE PADUA, 2005, p. 132).

Marsilio, como se puede advertir, no fundamenta lo que a simple vista se nos asemeja a la lógica contractual que veremos nacer en la Europa de los 
siglos XVI al XVIII, ni entra en la lógica procedimental de la administración del poder político que veremos desarrollar en la Europa de los siglos XIX y XX. Lo que este autor decanta, y desarrolla, son las implicancias de la distinción fundamental entre ley divina y ley humana. Todo parece derivarse de ello, incluidas las bases para decodificar algo como la legitimidad del poder ejercido coactivamente. Es esto, de hecho, lo que le permite observar, para incluir, aquello que llama "conjunto de los hombres", que a todas luces ya encarna una ruptura fundamental con el modelo jerarquizado, estamental del periodo medieval que le antecede.

Pero claro, Marsilio no habla de democracia en los términos de representación política a los que estamos acostumbrados. Lo que hace, es marcar los límites de competencia de un poder respecto del otro, y con claras consecuencias para el desempeño o rendimiento social en general, tal cual ocurrirá con su discusión en torno al matrimonio, el que, dicho sea de paso, no se considera cuestión espiritual, y por ende, ajeno a la competencia del clero, tal cual lo demuestra en el capítulo XIII de la obra en comento (MARSILIO DE PADUA, 2005, p. 138).

En tanto criterio de rendimiento social, la distinción de poderes, o de leyes (la divina o humana), y sus espacios de interferencia (ésta vida, o bien la otra vida) le facilita una clarificación que, según se advierte en la línea de argumentación teológica dominante desde el siglo XIII hasta el Concilio Vaticano II, queda perdida en el tiempo; a saber: la de las implicancias ético-morales, así como civiles, de creyentes y no creyentes, y tanto así, que para Marsilio bien han existido y pueden existir entre los infieles un imperio único y justo, cuestión que hace girar toda la preocupación habermasiana, así como la que se encuba desde Maquiavelo, pasando por el contractualismo, Kant, hasta nuestros días. A este respecto, nos permitimos presentar la nota $n^{\circ} 60$ de Bernardo Bayona y Pedro Roche de la ya citada obra del filósofo medieval; a saber:

En el contexto marsiliano el gobierno universal no se basa en la conquista por la fuerza, sino en el único interés de la justicia y la paz. Destaca la insistencia de Marsilio en reivindicar el carácter humanamente justo del imperium romano, tras dejar claro que también los gentiles han tenido gobiernos justos y no tiránicos y que, por tanto, el buen gobierno no se fundamenta en la doctrina religiosa. (MARSILIO DE PADUA, 2005, p. 133). 
Quizá valga cerrar esta parte de nuestro trabajo parafraseando a Habermas - Ratzinger; éste dirá: "Entre los miembros de una sociedad política solamente puede darse una solidaridad... cuando los principios de justicia han penetrado previamente el denso entramado de los diferentes conceptos culturales." (HABERMAS; RATZINGER, 2008, p. 20). Marsilio precisará sólo un criterio: dicha "penetración" será efectiva sólo si se reconoce la distinción fundamental entre ley divina y humana, que no son antagónicas, pero sí independientes y no sujetas a dominación alguna de una respecto a la otra ${ }^{6}$ y esto porque lo que se denomina aquí "solidaridad" no es sino cuestión humana.

II-B. La idea del gobierno universal, que citábamos no hace mucho, abre las puertas para una discusión en torno al imperativo del pluralismo, central en los márgenes del liberalismo político. ¿Podemos hablar de pluralismo en la filosofía política de Marsilio de Padua? Si esto fuese posible, ¿cómo se ajustaría una posición tal en el contexto de una discusión contemporánea donde la condición fundamental para lograr sociedades pluralistas, que vayan más allá de un mero modus vivendi, es la negación a toda autoridad no-humana, el total abandono a referencias de orden sacro-trascendental?

Para ahondar en este tema, y tratar de dar respuesta a estas interrogantes, tomemos la premisa fundamental que expone Rorty a este respecto.

De entrada, este autor advertirá que la posibilidad para una efectiva convivencia social pacífica, pluralista, entre distintas formas de vida ${ }^{7}$, descansa en la total renuncia a una autoridad no-humana, a un desprendimiento total de la metafísica, y de todo representacionalismo. En resumidas cuentas, y tal cual lo declara, una sociedad tal sólo será posible cuando la secularización se haya vuelto general, total (RORTY, 2000, p. 7). Ahora bien, ¿qué diferencia fundamental contendría una sociedad completamente secularizada respecto de aquellas que aún permanecen atadas y rebajadas a una autoridad no-humana?

\footnotetext{
${ }^{6}$ Estas relaciones develan, tal cual advertíamos, que Marsilio, pese a su ruptura y avance en las fundamentaciones que pronto tomarán para sí las democracias modernas, es y sigue siendo un pensador medieval. Pese a que estas dos leyes no son antagónicas, o que no deben someterse la una a la otra, ante una diferencia en el interior de ambas, bien prevalece una. Nuestro autor dirá: "Hay que señalar que si la ley divina prescribe hacer u omitir algo que la ley humana no prescribe hacer u omitir, sino más bien prescribe lo contrario, o lo permite, se debe observar el precepto de la ley divina y dejar de lado o ignorar la ley humana y su precepto o permisión contrarios, puesto que el precepto de la ley divina contiene una verdad infalible, el de la ley humana no." (MARSILIO DE PADUA, 2005, p. 141).

7 Entre distintas formas de vida orientadas por el principio que sostiene que ninguna de estas es superior y/o mejor que las demás.
} 
La respuesta es esta: una sociedad completamente secularizada descansaría en un consenso general en la suficiencia de lo bello; en una sociedad aún atada a una autoridad no-humana, pervive todavía un sentido de lo sublime.

La distinción fundamental aquí es la de bello/sublime. Así, por ejemplo: lo sublime, nos dirá Rorty, es irrepresentable; indescriptible; inefable; elude la finitud y, por lo tanto, también la unidad y la pluralidad; es moralmente ambigua. Lo bello, en cambio, armoniza cosas finitas con cosas finitas; permite contemplar algo manejable, algo que consta de unas partes reconocibles como organizadas de una forma reconocible. Sublimes son, a juicio de Rorty, la Idea de Bien de Platón, así como la idea cristiana de Pecado. La teología cristiana ortodoxa, a juicio del autor, siempre ha estado en contra de lo finitamente bello o feo, lo finitamente benévolo o perverso, y a favor de una distancia infinita entre nosotros y el ser humano que en vano procuramos imitar, tomando prestado, para construir su imaginario, el intento que realiza la filosofía griega para abstraerse de los propósitos humanos finitos (RORTY, 2000, p. 8 y ss). Una resultante de esta reducción hacia lo sublime la encontramos -a su entender- en la idea de ética y moral imperante en occidente desde Platón:

Desde Platón, Occidente ha considerado que la distinción razón/pasión es paralela a la distinción entre lo universal y lo individual, y a la distinción entre actos desinteresados y actos egoístas. De esta suerte, las tradiciones religiosas, platónica y kantiana nos han cargado con la distinción entre un yo verdadero y un falso yo, entre un yo atento a lo que le dice la consciencia y un yo que sólo está preocupado por su propio interés. Este último yo no llega a ser moral; es sólo prudencial. (RORTY, 2000, p. 207).

A juicio de Rorty, entre estas posturas y tensiones de orden éticomoral, y las dimensiones epistemológicas, se da una conexión que no hay que pasar por alto. Así, por ejemplo: el reconocimiento de lo sublime supone la existencia de seres, sujetos particulares que, por facultades cuya base también refiere a lo sublime, son capaces de reconocer la verdad de aquello que, por definición, trasciende su propio condicionamiento, es decir, el hecho de que son seres finitos y condicionados. Es una contradicción, o un contrasentido, que seres finitos y condicionados puedan acceder a objetos, a realidades entendidas o concebidas como infinitas e incondicionadas, tal cual lo sería todo aquello sublime. Que sólo algunos puedan acceder a esta realidad, a su representación, a la Verdad, deviene en un autoritarismo que sólo se legitima en universos de representación metafísica. Con Platón, según Rorty, y luego con Kant, este renegar de lo finito y condicionado 
pervierte la natural equivalencia de observaciones entre seres finitos y condicionados, estableciendo un fundamento filosófico, teológico, ético y político para una jerarquización cuya guía es el acceso privilegiado a la Verdad, y en cuanto tal, una franca negación a todo o cualquier tipo de pluralismo, de un pluralismo que vaya más allá de un simple modus vivendi, que fue la salida, dicho sea de paso, de los contractualistas ingleses en el contexto de las pugnas religiosas de los siglos XVI y XVII, que visto al detalle no resultó ser sino una salida instrumental de convivencia bajo el criterio de acceso privilegiado al mundo, a la realidad.

No conocemos texto donde Rorty acredite un conocimiento de los aportes de Marsilio de Padua. Si tuvo tal conocimiento, es cuestión que debemos dejar abierta. Dicho esto, cabe preguntarse por los cambios de perspectiva que habría tenido su propia filosofía si hubiera accedido a la distinción entre ley divina y ley humana -que en algunos aspectos hace eco de la distinción sublime/bello que el propio Rorty postula-, o a la idea de gobierno universal de Marsilio.

Pero no sólo eso. El autoritarismo que Rorty suele adjudicar a todos aquellos que reconocen y se reconocen en una autoridad no humana, o en todos aquellos que no descartan como recurso los criterios de orden metafísico, parece quedar en entredicho cuando se retoma el precepto que el paduano extiende sirviéndose de Ambrosio y de Crisóstomo; a saber: "No pretendemos dominar sobre vuestra fe". Ambrosio dirá: "No pretendemos dominar sobre vuestra fe, es decir, que vuestra fe no tenga que soportar sometimiento o coacción, ya que nace de la voluntad, no de la necesidad". Crisóstomo, por su parte, agregará:

\begin{abstract}
Hace falta que en la Iglesia cada uno se convierta hacia lo mejor, no por coacción, sino por aquiescencia... Pues las leyes no nos han conferido a nosotros -a obispos o presbíteros- tal poder o autoridad de sentencia para apartar a los hombres de las faltas, y, si nos hubiera sido dado, no tendríamos dónde ejercer ese poder, puesto que nuestro Dios, es decir, Cristo, recompensará no a aquellos que se han alejado del pecado por necesidad, o sea, por violencia, sino a los que se han apartado de él voluntariamente. $^{8}$ (MARSILIO DE PADUA, 2005, p. 130).
\end{abstract}

\footnotetext{
${ }^{8}$ No está de más hacer notar que esta idea de "voluntad", asociado al ejercicio de la libertad del hombre, de la libertad en sus decisiones fundamentales, seguirá vigente hasta adentrada la modernidad, o el periodo postilustrado. Tampoco está de más compartir la idea -formulada por Pannenberg- de que esta discusión en torno a la voluntad y la libertad será una de las pocas que, en el seno de las sociedades modernas, mantendrá vigente la fuente y base cristiana en el pensamiento occidental. $\mathrm{Al}$ respecto, véase Una historia de la filosofía desde la idea de Dios (PANNENBERG, 2002).
} 
Podríamos, a estos efectos, sumar otro criterio fundamental que sin duda parece aproximar, más de lo que muchos estarían dispuestos a aceptar, a Marsilio con una variante menos radical del pragmatismo de Rorty, quien, a estas alturas, parece dejarse llevar por el reduccionismo que sobre el medioevo se ha estilado hacer, en especial, los tiempos de monjes. Dicho criterio dice relación con una profundización, que parece remitir a Aristóteles, en torno a la diferencia entre ley divina y ley humana. Al respecto, el Paduano sostendrá lo siguiente: la ley divina y la ley humana difieren por la causa eficiente: la causa inmediata eficiente de los preceptos de la ley divina es Dios; mientras que la de la ley humana es el espíritu humano, o su elección o voluntad. Difieren también por su causa final: la de los preceptos de la ley divina es el gozo eterno de los hombres en la otra vida; sin embargo, la de la ley humana es la tranquilidad en esta vida y la felicidad finita.

Marsilio no asume, tal cual lo atribuye Rorty, una negación de la finitud y condicionalidad del hombre en base a sus creencias religiosas, o en base a fundamentos teológicos tradicionales. Todo lo contrario: la posibilidad de paz, así como los rendimientos sociales en todos sus niveles, como lo podría ser el matrimonio, descansan en, precisamente, reconocer la diferencia, la distinción entre ley humana y ley divina, entre los bello y lo sublime, mas sin negar la existencia y acceso a lo sublime, mas no tomándolo como condición de acceso privilegiado a rendimientos sociales y humanos contingentes. De ahí su esfuerzo central por cuestionar la jurisdicción eclesiástica, así como las atribuciones de un poder privilegiado dado por Dios clero, que, tal cual lo veíamos, parecen atentar en contra, precisamente, del fin último al que todos están destinados: la paz y la felicidad.

\section{A MOdo DE CONCLUSIÓN}

Una simple revisión delas discusiones, modelaciones y fundamentaciones políticas y sociales dadas al interior del periodo de tiempo conocido como Edad Media, nos permiten reconocer etapas que difieren y que denotan la diversidad intelectual en dicho periodo. Esto nos aleja, o nos da luces críticas respecto al reduccionismo con el que se suele caracterizar al medioevo. Los "tiempos de monjes", tan gravitantes en la visión orgánica y estamentaria de la sociedad -como trasfondo para el fundamento del primado del poder de la Iglesia respecto al Estado-, es sólo un periodo y en caso alguno la condicionante general durante la Edad Media. Así, concebir la Edad Media como un 
tiempo de plena y absoluta dominación clerical, sin espacio o posibilidad alguna para el pensamiento crítico, o para fundamentaciones filosóficos y políticas alternativas, confrontacionales, es un error que, si bien resulta no poco generalizado, decae, o se derrumba al conocer los aportes de Marsilio de Padua. Para denotar lo significativo de esto, hemos, por medio del rescate de los problemas centrales del liberalismo político planteados por Habermas, tensionado los aportes del Paduano de forma tal de, sin caer en los extremos de ver en él un fundador de las democracias modernas, o bien contemporáneas, o de ver en las democracias modernas un mero plagio de los aportes del filósofo medieval, reconocer que dichos problemas ya se encuentran contenidos en la filosofía política de este autor, y lo que es aún más importante, advertir que, si bien no inmerso en la semántica democrática, Marsilio sí integra y da perspectiva a los problemas en torno a lo que hoy conocemos como secularización para los rendimientos políticos cuya fundamentación renuncia a los criterios religiosos, así como en torno a las expectativas tanto cognitivas como normativas en contextos donde se imponga la ley humana como criterio de convergencia en torno a un valor como el de la solidaridad político-social.

Pero un conocimiento semejante nos ha permitido, además, reconocer ya para el siglo XIV, la existencia de criterios acordes, o próximos, con el imperativo del pluralismo, colocando en entredicho, de paso, los reduccionismo que Rorty establece y que le hacen ver en todo el universo de representaciones metafísicas, o sacro-trascendentales, un freno, o una franca negación de un tipo de sociedad pluralista. Los aportes del filósofo de Padua nos permiten arriesgar la idea de que pluralismo y religión no se contraponen en todo; es más: Marsilio nos muestra que al interior de una sociedad que no ha renunciado a la religión se pueden establecer criterios tendientes a una convivencia efectiva entre creyentes y no creyentes, sin que ninguna de las partes tenga el monopolio del justo y pacífico gobierno.

ESCUDERO, M. C.; VALLEJOS, R. C. Contemporary democracy and its medieval foundations: Marsilius of Padua and the rational justification of the normative principles of the state. Trans/form/ação, Marília, v. 41, n. 2, p. 55-72, Abr./Jun., 2018. 
ABSTRACT: Through the works of Marsilius of Padua we trace sources and references that, in the context of thirteenth and fourteenth century discussions, may be seen on the margins of the foundations of contemporary democracy. The article discusses arguments related to political liberalism (Habermas), the imperative of pluralism (Rorty), and a broadening of the characterization of the social and political thinking of the Middle Ages.

KEYwords: Medieval political thinking. Contemporary democracy. Political liberalism. Pluralism.

\section{REFERENCIAS}

HABERMAS, J.; RATZINGER, J. Entre razón y religión: dialéctica de la secularización. Ciudad de México: Fondo de Cultura Económica, 2008.

JUAN DE SALISBURY. Policraticus. Madrid: Nacional, 1984.

MARSILIO DE PADUA. El defensor de la paz. Madrid: Tecnos, 2009.

. Sobre el poder del imperio y del papa: el defensor menor: la transferencia del imperio. Madrid: Biblioteca Nueva, 2005.

PANNENBERG, W. Una historia de la filosofía desde la idea de Dios. Salamanca: Sígueme, 2002.

RODRIGUEZ, D.; TORRES, J. Introducción a la teoría de la sociedad de Niklas Luhmann. México: Herder, 2008.

RORTY, R. El pluralismo, una versión: antiautoritarismo en epistemología y ética. Barcelona: Ariel, 2000.

VON GIERKE, O. Teorias politicas de la Edad Media. Madrid: Centro de Estudios Constitucionales, 2010.

Recebido:15/01/2016

Aprovado: 08/05/2017 